\title{
EVALUACIÓN OPERACIONAL DEL SISTEMA DE TRATAMIENTO DE AGUAS RESIDUALES DE LA CIUDAD DE ESTELÍ, NICARAGUA.
}

\section{OPERATIONAL EVALUATION OF THE WASTEWATER TREATMENT SYSTEM IN ESTELI, NICARAGUA}

\author{
Henry Javier Vílchez Pérez ${ }^{9}$ \\ Walter Isaac Pinell Centeno ${ }^{10}$ \\ Francisco Antonio López Valdivia ${ }^{11}$
}

RESUMEN: El presente trabajo se realizó con el objetivo de evaluar la eficiencia, operación y mantenimiento del Sistema de Tratamiento de Aguas Residuales de la ciudad de Estelí, a través de la determinación de los parámetros fisicoquímicos y bacteriológicos establecidos en los Artos. 22 y 23 del Decreto 33-95 y la norma NTON 0502705 . El Sistema de tratamiento evaluado está compuesto por 3 módulos independientes, cada módulo constituido por tres unidades de tratamiento (UASB + laguna facultativa + maduración). Para la determinación de las variaciones de caudal en la entrada y salida del STAR se realizaron aforos por tres días consecutivos con frecuencia de $8 \mathrm{~h}$, utilizando canales rectangulares y canaletas parshall para conocer el caudal de afluente y efluente. El muestreo se llevó a cabo; durante 3 días consecutivos, se analizaron los siguientes parámetros: temperatura del agua, sólidos suspendidos totales, sólidos sedimentables, DBO5, DQO, grasas y aceites, sustancias activas al azul de metileno y coliformes fecales, los cuales a través de análisis de laboratorio brindaron la información necesaria sobre el funcionamiento del sistema. Las muestras compuestas se efectuaron en la entrada y salida general del STAR donde se realizaron seis muestreos por tres días consecutivos, con frecuencia de 10h. Las muestras simples se realizaron durante un día con frecuencia de $1 \mathrm{~h}$, en la entrada y salida de los reactores UASB y lagunas de estabilización que comprende cada módulo. La eficiencia total del sistema según la remoción de $\mathrm{DBO}_{5}$, DQO y coliformes fecales fue de $92.48 \%, 86.95 \%$ y $81.16 \%$ respectivamente, sin embargo el porcentaje de remoción de coliformes no es lo suficiente para cumplir con los Art 22 y 23 del Decreto 33-95.

PALABRAS CLAVE: $\mathrm{DBO}_{5}, \mathrm{DQO}$, grasas y aceites, sustancias activas al azul de metileno y coliformes fecales

\footnotetext{
9 Docente/Investigador del Programa de Investigación, Estudios Nacionales y Servicios Ambientales, PIENSA Universidad Nacional de Ingeniería, UNI jvil12p@gmail.com o Henry.Vilchez@piensa.uni.edu.ni Apartado Postal: 5595

${ }^{10}$ Egresado de la carrera de Ingeniera Civil, UNI - RUACS, Nicaragua

${ }^{11}$ Egresado de la carrera de Ingeniera Civil, UNI - RUACS, Nicaragua
} 
ABSTRACT: The present work was carried out with the objective of evaluating the efficiency, operation and maintenance of the Wastewater Treatment System of the city of Estelí, through the determination of the physicochemical and bacteriological parameters established in the Artos. 22 and 23 of Decree 33-95 and the standard NTON 0502705 . The treatment system is composed of 3 independent modules, each module consisting of 3 treatment units (UASB + facultative lagoon + maturation). For the determination of the flow variations at the entrance and exit of the STAR, measurements were made for three consecutive days with a frequency of $8 \mathrm{~h}$, using rectangular channels and parshall channels to know the flow of tributary and effluent. Sampling was carried out during 3 consecutive days of sampling the following parameters were analyzed: water temperature, total suspended solids, sedimentable solids, BOD5, COD, fats and oils, methylene blue and fecal coliforms, which through laboratory analysis provided. The necessary information on the operation of the system. The composite samples were made at the general entrance and exit of the STAR where six samplings were carried out for three consecutive days, with frequency of $10 \mathrm{~h}$. The simple samples were run for one day with a frequency of $1 \mathrm{~h}$, at the entrance and exit of the UASB reactors and stabilization ponds comprising each module. The total efficiency of the system according to the removal of BOD5, COD and fecal coliforms was $92.48 \%, 86.95 \%$ and $81.16 \%$ respectively, however the percentage of coliform removal is not enough to comply with Art 22 and 23 of Decree 33 -95.

KEYWORDS: $\mathrm{BOD}_{5}, \mathrm{COD}$, fats and oils, active substances to methylene blue and fecal coliforms.

\section{INTRODUCCIÓN}

Las lagunas de estabilización son una opción viable para el tratamiento de aguas residuales en países en desarrollo; los costos de operación son bajos, se garantiza la remoción de la materia orgánica, demanda bioquímica de oxígeno DBO y coliformes fecales con unidades de número más probable NMP/100 mL (Rolim, 2000).

El sistema de tratamiento de aguas residuales de la ciudad de Estelí, trabaja por medio de lagunas de estabilización del tipo facultativa, es decir que operan en la primera parte como lagunas anaerobias y después con la presencia de bacterias (facultativas) como lagunas facultativas y dichas aguas residuales tratadas son vertidas a la Quebrada La Limonosa, afluente del rio Estelí. EI STAR está compuesto por 3 módulos de tratamiento, cada módulo está constituido de la siguiente manera: Upflow Anaerobic Sludge Blanket (UASB) + Laguna Facultativa (LF) + Laguna de Maduración (LM).

El sistema de tratamiento de aguas residuales (STAR) del municipio de Estelí se encuentra ubicado en la salida norte de la ciudad, en las siguientes coordenadas geográficas: $13^{\circ}$ $6^{\prime} 37.67 " \mathrm{~N} 86^{\circ} 21^{\prime} 43.94$ "O y fue construido con un sistema de pretratamiento compuesto por dos rejillas gruesas y una rejilla fina, un desarenador y un tratamiento secundario por medio de lagunas facultativas que formaban parte de tres módulos de tratamiento ( $A, B$ y $C$ ) que comprendía el STAR con el fin de operar paralelamente. 
De acuerdo a ENACAI (2015), el diseño del primer módulo de tratamiento "A" fue presentado por la Dirección de diseño y construcción del INAA en 1985 y construido en 1986 con fondos del gobierno de Nicaragua. El financiamiento del módulo "B" se consiguió por medio de fondos alemanes a través de las "Casas hermanas" y él modulo "C" fue construido en el año 1994 con ayuda del financiamiento de la Agencia Española para el Desarrollo (ACEDI). Cabe destacar que los módulos "B y C" siguieron las especificaciones de diseño que el INAA elaboró para el módulo "A". El caudal de diseño del STAR para esos 3 módulos era de $100 \mathrm{~L} / \mathrm{s}$.

La primera rehabilitación que se le realizó a este sistema de tratamiento de aguas residuales (STAR) fue en 1995 al módulo "A" y entre los años 1999 y 2000 a los módulos "B" y "C", después del Huracán Mitch (octubre de 1998).

Todos estos cambios fueron requeridos debido a que el sistema era ineficiente, porque no cumplía con los valores máximos de los parámetros DBO5, DQO Y coliformes fecales establecidos en los arto. 22 y 23 del Decreto 33-95 y se requería de un sistema que tratara mayor volumen de aguas residuales, debido que la población de la ciudad de Estelí que tenía acceso al sistema de alcantarillado sanitario había aumentado considerablemente un $50 \%$ en los últimos años.

Las evaluaciones y monitoreos periódicos realizados al STAR a través de los laboratorios del Centro de Investigaciones de Recursos Acuáticos de la Universidad Nacional Autónoma de Nicaragua (CIRA - UNAN, 2002), se logró analizar incumplía con varios parámetros establecidos en del Decreto 33-95. Entre los parámetros que incumplía dicha planta de tratamiento se encontraban grasas, aceites, DQO, DBO5, sólidos suspendidos totales y coliformes fecales, lo cual dio paso a realizar un mejoramiento del STAR al módulo "A" entre julio y octubre del 2003 y a los módulos B y C entre diciembre 2003 a octubre del 2004.

Se amplió la capacidad de 100 a 300 L/s, que es el caudal proyectado para el año 2024. Todo esto se logró después de realizar una serie de modificaciones en la combinación existente de Lagunas Facultativas primarias (LF) + Lagunas Aerobias secundarias (LA), por un sistema de Upflow Anaerobic Sludge Blanket (UASB) + Laguna Facultativa (LF) + Laguna de Maduración (LM).

Así también se realizó la ampliación de la capacidad de tratamiento del volumen de aguas residuales proveniente de la Red de Alcantarillado Sanitario (RAS), para que el efluente del STAR cumpliera con lo especificado en los artículos № 22 y 23 del Decreto 33-95.

Debido a lo mencionado anteriormente, esta investigación se realizó con el objetivo de diagnosticar el funcionamiento de la planta de tratamiento de aguas residuales municipales de la ciudad de Estelí, logrando de esta manera obtener nueva información sobre la operación del sistema de tratamiento por lagunas de estabilización, mediante un análisis de su eficiencia y funcionamiento, lo cual podrá considerarse como punto de referencia para comprobar el estado de la planta de tratamiento municipal en lo respectivo al cumplimiento de los parámetros establecidos en los artos. № 22 y 23 del Decreto 33-95, así como la norma NTON 05 027-05. 
Por lo descrito en el párrafo anterior, este estudio nos servirá para plantear una solución que contribuya a mejorar la eficiencia del sistema de tratamiento, lo cual beneficiara las condiciones ambientales del cuerpo receptor y de la población que reside en los márgenes del STAR.

\section{METODOLOGÍA}

La investigación tendrá un enfoque mixto ya que se realiza una descripción de la zona de estudio, para obtener información actualizada sobre su funcionamiento. Según el alcance temporal el estudio es de corte trasversal, debido a que se refiere a un momento especifico. Según el carácter de la medida de enfoque del estudio es mixto, se analizaron y vincularon datos cuantitativos y cualitativos.

Para dar cumplimiento a los objetivos se realizaron las siguientes etapas:

\section{- I Etapa:}

Esta etapa se realizó con el fin de conocer a profundidad el problema y las posibles soluciones, abarcando los siguientes aspectos:

Reconocimiento del sitio de estudio:

El sistema de tratamiento de aguas residuales de la ciudad de Estelí, está conformado por tres módulos independientes, cada módulo constituido por tres lagunas (anaerobia, facultativa y aerobia), pero esencialmente el sistema se compone por un tratamiento preliminar, un tratamiento primario y un tratamiento secundario, con el objetivo de mejorar la calidad del agua residual que ingresa al STAR, proveniente del alcantarillado sanitario de la ciudad y luego ser vertida al cuerpo receptor (Quebrada "La Limonosa").

\section{Tratamiento preliminar}

En este tratamiento se da el proceso de eliminación de materiales, que podrían perjudicar el sistema de conducción de la planta. El objetivo principal de este tratamiento es acondicionar el agua residual a fin de que esta pueda pasar a las demás etapas de tratamiento sin afectar la operación de los mismos, ver esquema 1.

\section{Tratamiento primario}

El objetivo de este tratamiento es remover aquellos contaminantes como sólidos sedimentables y suspendidos por medio de sedimentación, flotación, filtración y precipitación. Para este tratamiento el STAR posee en cada módulo un UASB (Reactor anaeróbico de flujo ascendente), ver esquema 2.

\section{Tratamiento Secundario}

Esta etapa del sistema de tratamiento consta de dos lagunas en serie (facultativa y maduración) en cada módulo, tienen como función principal la remoción del material contaminante a través de procesos bioquímicos, en los cuales los microorganismos son los encargados de la degradación de la materia orgánica contenida en las aguas residuales, ver esquema 3. 


\section{Efluente General STAR - Estelí}

El tratamiento realizado en cada uno de los módulos produce un efluente verde por su alto contenido de algas, el cual es recolectado en un canal subterráneo para ser vertido al cuerpo receptor que es la Quebrada la Limonosa, afluente del rio Estelí.

Este efluente se observa que tiene muchas espumas esto se debe a que el canal genera turbulencia provocando las espumas que son un indicador a su vez de presencia de los detergentes que no se remueven en el sistema, ver esquema 4.

\section{Esquema 1: Tratamiento preliminar}

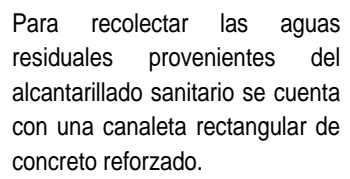

Para la medición de caudales de entrada, el STAR posee una canaleta parshall con una regla graduada $(1 \mathrm{~m})$.

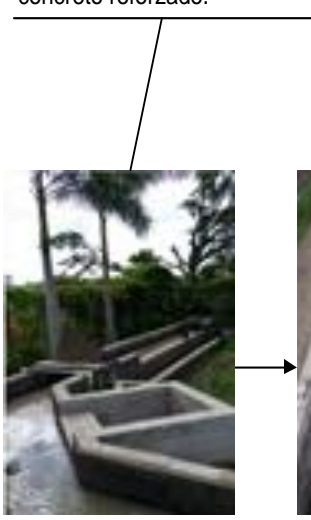

Con el objetivo de retener y separar sólidos que provienen del desarenador, así como evitar obstrucciones en los canales, se cuenta con una rejilla fina.

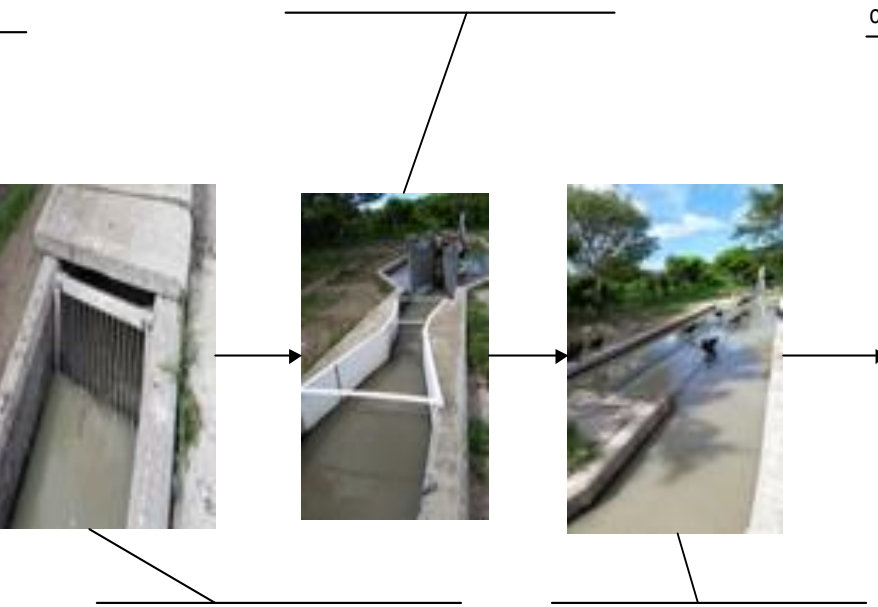

Debido al gran contenido de sólidos que poseen las Aguas residuales se puede llegar a afectar las demás unidades, es por eso que para evitar el paso de estos, existe una rejilla gruesa de acero con inclinación de $45^{\circ}$.
Con la función principal de remover aquellos sedimentos que pueden afectar el funcionamiento de los módulos se cuenta con un desarenador de flujo horizontal.

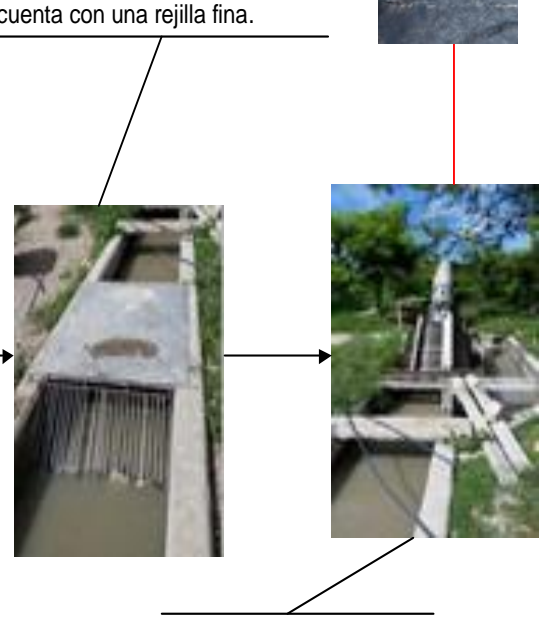

La fase final del tratamiento preliminar la realiza el tamiz de tornillo directo, el cual remueve las partículas finas que entran al sistema.

Esquema 1. Tratamiento primario 


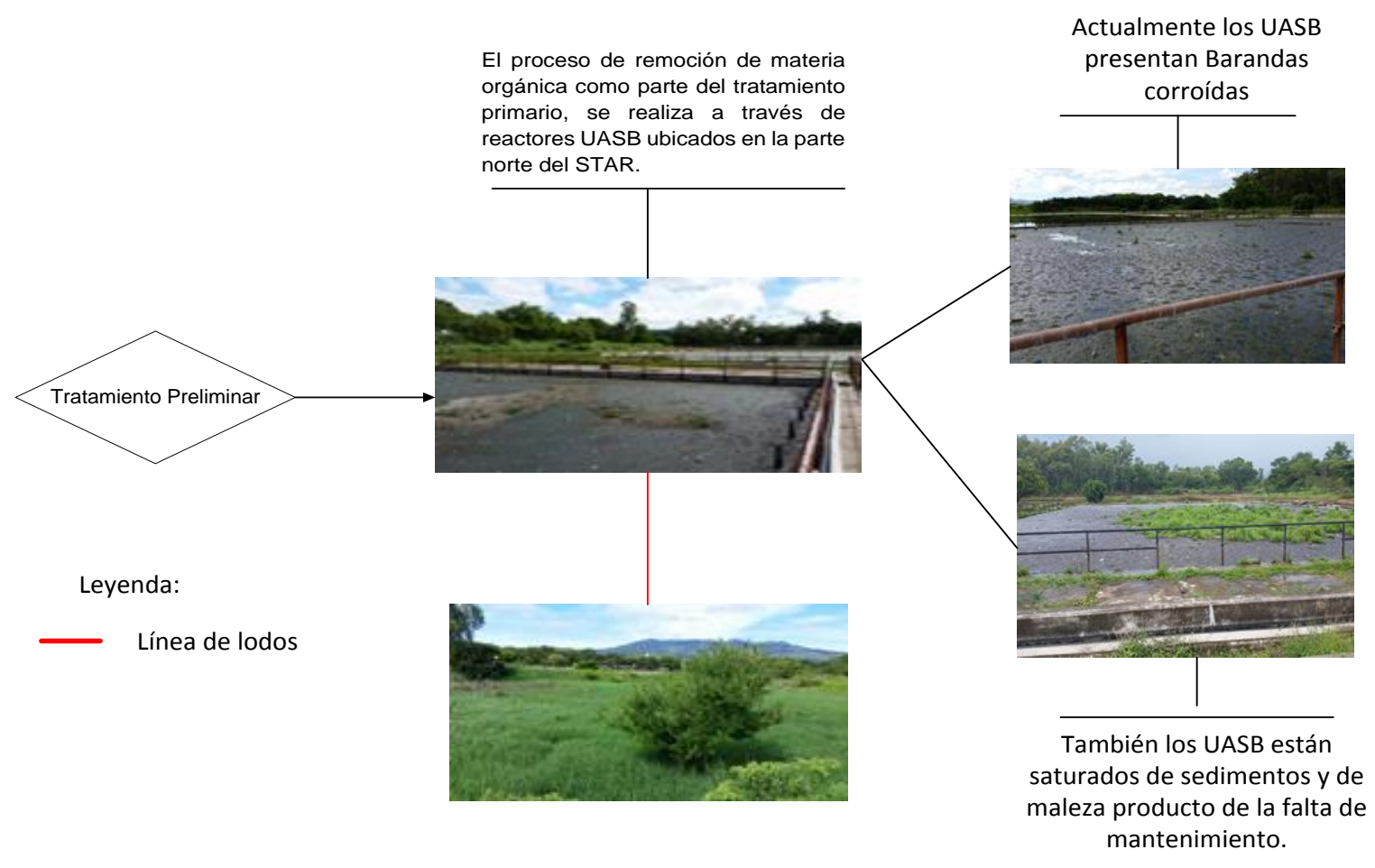

Esquema 3. Tratamiento secundario

El efluente general presenta un color verde y espumas en sus aguas, debido al alto contenido de algas y a que los lavaderos de carros están conectados a la red de alcantarillado sanitario.

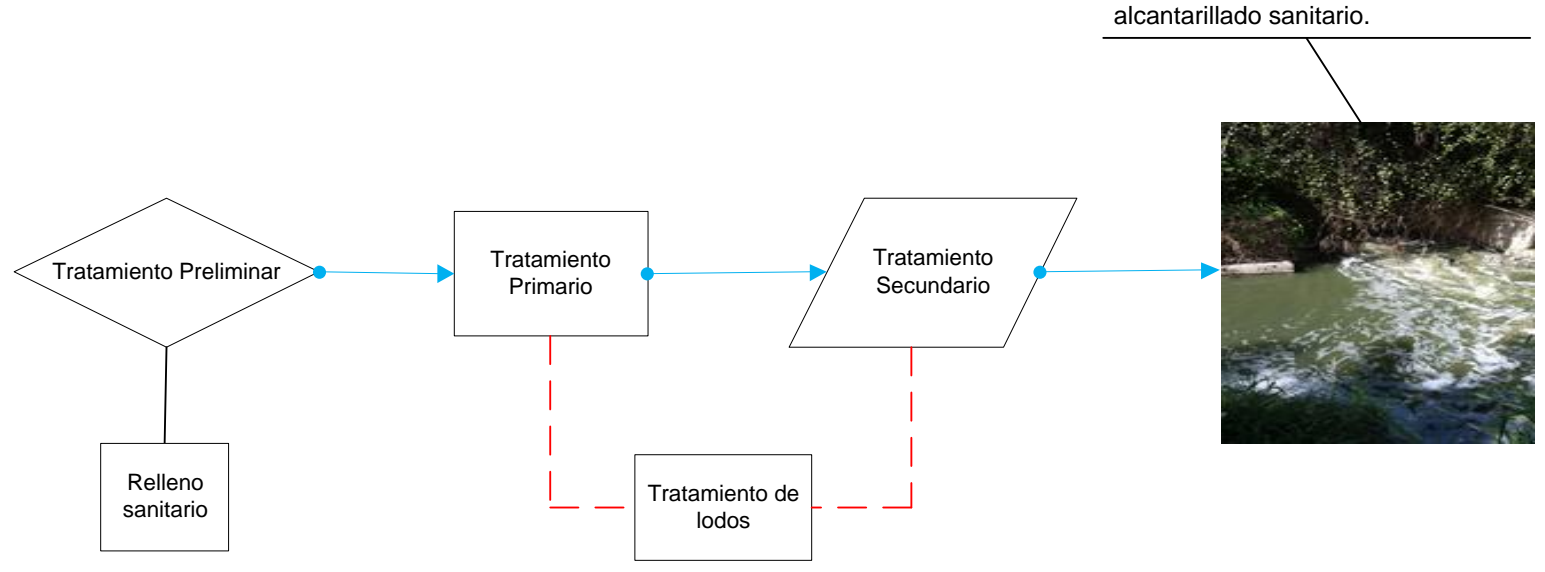

Leyenda:

Línea de lodos

$\longrightarrow$ Línea de agua

Esquema 2 Efluente Final 


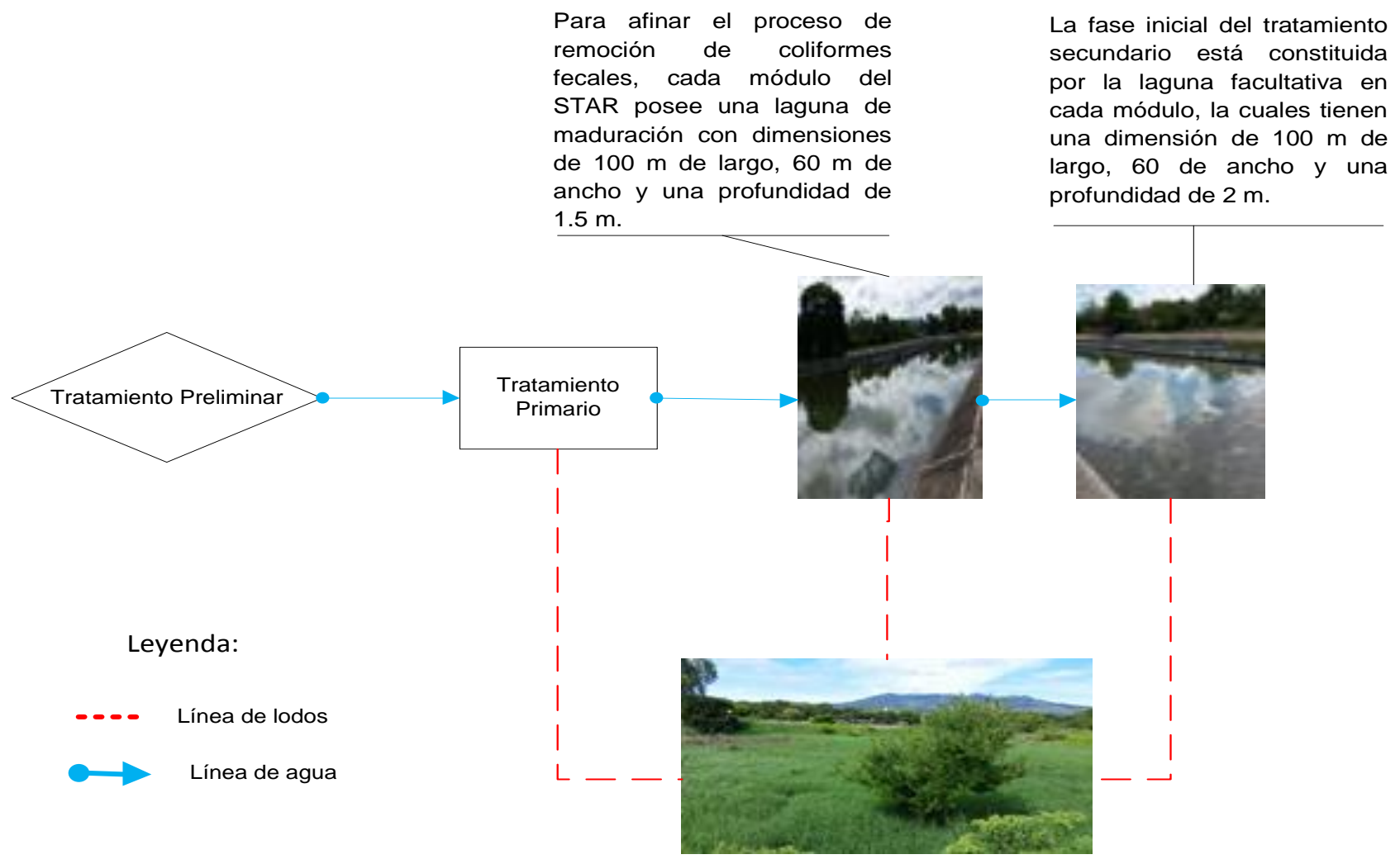

\section{Selección de los puntos de muestreos y de medición del caudal}

La medición de los caudales de la entrada y salida general del STAR se realizó en la canaleta parshall y canal de descarga; así como también los caudales de entrada y salida de cada módulo se realizó en los canales rectangulares que comprenden cada uno de los módulos, para determinar del comportamiento del flujo en el transcurso del tiempo establecido.

Para lograr el objetivo planteado de determinación de variación de caudal en la entrada y salida del STAR se utilizó el siguiente procedimiento:

Se realizaron 3 aforos de 8 horas durante el periodo comprendido de tres días.

\section{Muestreo de aguas residuales}

Para el muestreo se definieron 14 puntos diferentes, los cuales corresponden a la entrada y salida general del STAR, así también las entradas y salidas de las unidades de tratamiento que conforman los módulos.

Las muestras compuestas se efectuaron en dos puntos distintos (afluente y efluente) donde se realizaron seis muestreos por tres días consecutivos, con frecuencia de 10h/día. También, se efectuaron una serie de muestreos puntuales durante un día con frecuencia de 3h/día en el 
afluente y efluente de cada laguna del STAR. En la tabla siguiente se especifica la frecuencia de muestreo.

\section{Parámetros físicos-químicos evaluados}

Los parámetros medidos en el campo fueron $\mathrm{pH}$ y temperatura. El resto de los parámetros físicos químicos como son Sólidos Sedimentables, Grasa y aceites, DBO5, DQO, Sólidos Suspendidos y microbiológicos (Coliformes fecales), se determinaron en el Laboratorio Central de ENACAL y una parte en el Laboratorio de PIENSA-UNI.

\section{Determinación del tiempo de retención}

El período de retención para cada laguna del sistema se determinó de manera teórica, se obtuvieron los valores de la relación entre los volúmenes de cada laguna tomando en cuenta los caudales promedios del balance hídrico (OPS/CEPIS, 1996).

$$
T R H=\frac{V}{\text { Qmedio }} \quad \text { Ecuación } 1 .
$$

\section{Dónde:}

TRH = Tiempo de retención Hidráulico (días); $\mathbf{Q}=$ Caudal $\left(\mathrm{m}^{3} / \mathrm{d}\right) ; \mathbf{V}=$ Volumen $\left(\mathrm{m}^{3}\right)$

\section{Procesamientos de datos}

Se procesaron y analizaron los resultados de los diferentes parámetros obtenidos en campo y en el laboratorio, los cuales se presentan como valores promedios con el fin de evaluar la eficiencia y funcionamiento del STAR.

\section{Métodos de cálculos aplicados para lagunas de estabilización}

\section{Carga orgánica}

Para la determinación de la carga orgánica se obtiene mediante la ecuación de Yánez:

$$
\mathrm{Co}=\mathrm{Q} \times \mathrm{DBO5} \times 0.0864 \quad \text { Ecuación } 2
$$

\section{Dónde:}

$\mathbf{C O}=$ Carga Orgánica; $\mathbf{Q}=$ Caudal; $\mathbf{D B O}_{5}=$ Concentración de $\mathrm{DBO}_{5}$

\section{Determinación de carga superficial limite admisible para lagunas facultativas}

Para obtener la carga superficial máxima para lagunas facultativas se utilizará el modelo cinético desarrollado por CEPIS a través de estudios de campo realizados por Yánez, el cual a través de procesamiento de datos concluyó que para cargas por encima de $357.4 \mathrm{Kg} / \mathrm{Ha}$ *Día predominan los procesos anaeróbicos.

A continuación con la siguiente correlación reportada por Yánez (1992), se estima la carga máxima admisible: 


$$
\text { Csm }=357.4 \text { * } 1.085 \mathrm{~T}-20 \quad \text { Ecuación } 3
$$

\section{Dónde:}

$\mathrm{T}$ : la temperatura del agua en ${ }^{\circ} \mathrm{C}$, en el mes más frío.

\section{Carga orgánica superficial máxima a aplicar}

Para determinar la Carga orgánica superficial máxima a aplicar es necesario utilizar la siguiente ecuación:

$$
\text { Csa }=\text { Csm * } 0.90 \quad \text { Ecuación } 4
$$

\section{Regulaciones ambientales}

Decreto 33-95: "Disposiciones para el control de la contaminación proveniente de las descargas de las aguas residuales domésticas, industriales y agropecuarias".

Arto.22.Los límites máximos permisibles de coliformes fecales medidos como número más probable no deberá exceder de 1000 por cada 100 en el $80 \%$ de una serie de muestras consecutivas y en ningún caso superior a 5000 por cada $100 \mathrm{ml}$.

Arto.23. Los parámetros de calidad de vertido luido provenientes de los Sistemas de tratamientos de los alcantarillados que sean descargados directa o indirectamente a los cuerpos receptores, deberán cumplir en los rangos y límites máximos permisibles expresados Para una población mayor de 75,000 habitantes.

\section{RESULTADOS Y DISCUSIÓN}

Como resultado de los aforos realizados durante 3 días consecutivos con una frecuencia de $8 \mathrm{~h}$ se obtuvo un gráfico de los caudales de la entrada y salida del STAR. De acuerdo a los resultados obtenidos del aforo realizado al STAR, el caudal promedio de entrada fue de 244.03 It $/ \mathrm{s}$, equivalente a $21,084.19 \mathrm{m3} / \mathrm{d}$, correspondiente al $81.34 \%$ de la capacidad de diseño $25,920 \mathrm{~m} 3 / \mathrm{d}$ y el caudal promedio de salida fue de $214.41 \mathrm{lt} / \mathrm{s}$. Los promedios diarios de los días aforados en la entrada se encuentran entre un mínimo de 239.39 lt/s y un máximo de $246.81 \mathrm{lt} / \mathrm{s}$ y en la salida el caudal mínimo es de $213.21 \mathrm{lt} / \mathrm{s}$ y el máximo de $216.52 \mathrm{lt} / \mathrm{s}$.

Los valores anteriores no indican el comportamiento de los caudales que ingresan y egresan del sistema, esto es producto de las actividades diarias y de producción de la población.

\section{Capacidad hidráulica}

En la tabla 1, se presenta los caudales promedios de entrada de cada laguna del STAR, considerando el tirante promedio se obtuvo la capacidad hidráulica de cada laguna y además se muestran los tiempos de retención teórico de cada laguna de estabilización.

Tabla 1: Capacidad hidráulica de las Laguna de estabilización

Modulo Caudal Volumen Tiempo retención




\begin{tabular}{lccc}
\hline & $\left(\mathrm{m}^{3} / \mathrm{d}\right)$ & $\left(\mathrm{m}^{3}\right)$ & (dlia) \\
\hline Laguna Facultativa Módulo A & $7,209.22$ & $16,733.34$ & 2.32 \\
Laguna Facultativa Módulo B & $6,880.90$ & $16,733.34$ & 2.43 \\
Laguna Facultativa Módulo C & $6,994.08$ & $16,733.34$ & 2.39 \\
Laguna Maduración Módulo A & $6,644.16$ & 8,899 & 1.34 \\
Laguna Maduración Módulo B & $6,340.90$ & 7,753 & 1.22 \\
Laguna Maduración Módulo C & $6,445.44$ & 8435 & 1.31 \\
\hline
\end{tabular}

De acuerdo a los resultados obtenidos en la tabla anterior, nos indican que las lagunas no realizan una completa remoción de patógenos debido a que los tiempos de retención no se encuentran dentro del rango recomendado (7-10 días) por la bibliografía especializada, como son CEPIS, Mara \& Silva (1969), Yánez (1980), McGarry \& Pescod (1970) entre otros, por lo cual esto afecta en la eficiencia remocional de Coliformes fecales y en el cumplimiento de los Art. 22 y 23 del Decreto 33-95.

\section{Balance Hídrico}

De acuerdo a los resultados obtenidos a través del balance hídrico estos nos indican que existen pérdidas de hasta $30.04 \mathrm{lt} / \mathrm{s}$ en todo el sistema de tratamiento, considerando que la evaporación incidió durante el periodo que se realizaron los aforos, y que además hay lagunas que presentan agrietamiento en los taludes lo cual favorece a la perdida de agua.

\section{Resultados de los análisis físico-químicos y bacteriológicos}

En esta sección se presentan los resultados de los análisis físico-químicos y bacteriológicos obtenidos en el laboratorio de ENACAL y de PIENSA, a partir del muestreo compuesto realizado al STAR en general y el muestreo puntual realizado a los módulos A, B y C respectivamente, ver tabla 2 .

Tabla 2: Resultados de análisis de laboratorios de los parámetros físicos, químicos y bacteriológicos del afluente y efluente general del STAR.

\begin{tabular}{lllll}
\hline \multicolumn{1}{c}{ Parámetros } & \multicolumn{1}{c}{$\begin{array}{c}\text { Entrada } \\
\text { General- STAR }\end{array}$} & $\begin{array}{c}\text { Salida } \\
\text { General- } \\
\text { STAR }\end{array}$ & $\begin{array}{c}\text { Cumplimiento } \\
\text { Art. 22 y 23 del } \\
\text { Decreto 33-95 }\end{array}$ & $\begin{array}{c}\text { Criterios según el tipo } \\
\text { de categoría de riego } \\
\text { (NTON 05 027-05) }\end{array}$ \\
\hline $\begin{array}{l}\text { pH campo } \\
\text { pH laboratorio }\end{array}$ & 6.93 & 6.88 & Cumple & - \\
SST $(\mathbf{m g} / \mathbf{l})$ & 7.05 & 6.85 & Cumple & - \\
Grasas y Aceites Totales $(\mathbf{m g} / \mathbf{l})$ & 228.15 & 26.45 & Cumple & - \\
SD $(\mathbf{m g} / \mathbf{l})$ & 17.43 & 3.28 & Cumple & - \\
DBO5 $(\mathbf{m g} / \mathbf{l})$ & 0.50 & 0.17 & Cumple & - \\
DQO $(\mathbf{m g} / \mathbf{l})$ & 288.58 & 21.71 & Cumple & Cumple \\
Sustancias Activas de Azul de & 414.32 & 54.08 & Cumple & - \\
Metileno $(\mathbf{m g} / \mathbf{l})$ & 1.26 & 0.56 & Cumple & - \\
CF (NMP/100) & $1.66 \mathrm{E}+07$ & $3.13 \mathrm{E}+06$ & No Cumple & No cumple \\
\hline
\end{tabular}

En la tabla 2, podemos observar la caracterización que se le realizó al afluente y efluente general del STAR. De acuerdo a los parámetros fisicoquímicos que se muestran en la tabla 2 
podemos decir que estos cumplen con los Art № 22 y 23 del Decreto 33-95 y la Norma NTON 05 027-05, a excepción del parámetro microbiológico como son los coliformes fecales, lo cual indica que el efluente tratado no es apto para ser directamente vertido al cuerpo receptor (La quebrada la Limonosa) y por lo que para ser reutilizable con fines agrícolas se deberá de hacer un análisis de a detalle de sus parámetros físicos, químicos bacteriológicos y tomar en cuenta el análisis de huevos helminto pero con estas característica puede ser reutilizable como riego de cultivos perennes.

Por lo tanto se puede decir que de acuerdo a estos resultados, que la reducción de concentración de dichos parámetros en el efluente es bastante aceptable, lo cual es un indicador de que el STAR trabaja de manera eficaz en la remoción de materia orgánica.

Las concentraciones encontradas de coliformes fecales en este sistema de tratamiento está lejos de cumplir con los parámetros de vertido pero este fenómeno es recurrente en los sistemas lagunares de Nicaragua por lo tanto no se lograra cumplir con el Decreto 33-95, ver gráfico 1.

Este problema no solo es en Nicaragua, es incipiente en los países de América Central debido a normas legisladas no adecuada que enfrente los problemas de patógenos discutidos anteriormente. En este respecto es importante que los ingenieros sanitarios y otros profesionales involucrados en salud pública desarrollen normas de diseño y nivel de tratamiento requerido para remover los patógenos que realmente causan los problemas de salud.

Existen pocos estudios científicos de los cuerpos receptores y el grado del tratamiento requerido para proteger la salud y el cuerpo receptor, y probablemente no van a existir en un futuro cercano (la carencia de esos estudios es un problema de todos los países centroamericanos).

Por lo tanto, es importante buscar soluciones que estén basadas en los problemas fundamentales a la salud pública en vez del cuerpo receptor. Debido a que los problemas más urgentes en Centroamérica son las enfermedades relacionados con las excretas, se puede concluir que la remoción de patógenos es la norma más importante. Sin embargo, hay que tomar en cuenta que en otros países como los Estados Unidos, el problema es totalmente diferente y por lo tanto, la tecnología requerida allá puede ser muy diferente también; es por eso que el uso de plantas de lodos activados es común en los Estados Unidos pero no apropiado para muchas aplicaciones en Centroamérica.

Además se debe considerar que según Shuval et al. (1986) que las infecciones por helmintos constituyen el riesgo más peligroso para la salud en relación con el tratamiento de aguas residuales cuando se utiliza el efluente para riego (uso directo o indirecto de agua superficial contaminada), una práctica común en América Latina que ha causado los problemas a la salud pública. Se concluyeron que después de las infecciones de helmintos, en orden de riesgo por las infecciones serían las de protozoarios, bacterias, y finalmente los virus. 
En el gráfico 1, se muestran la concentración de coliformes fecales en el afluente y efluente del STAR.

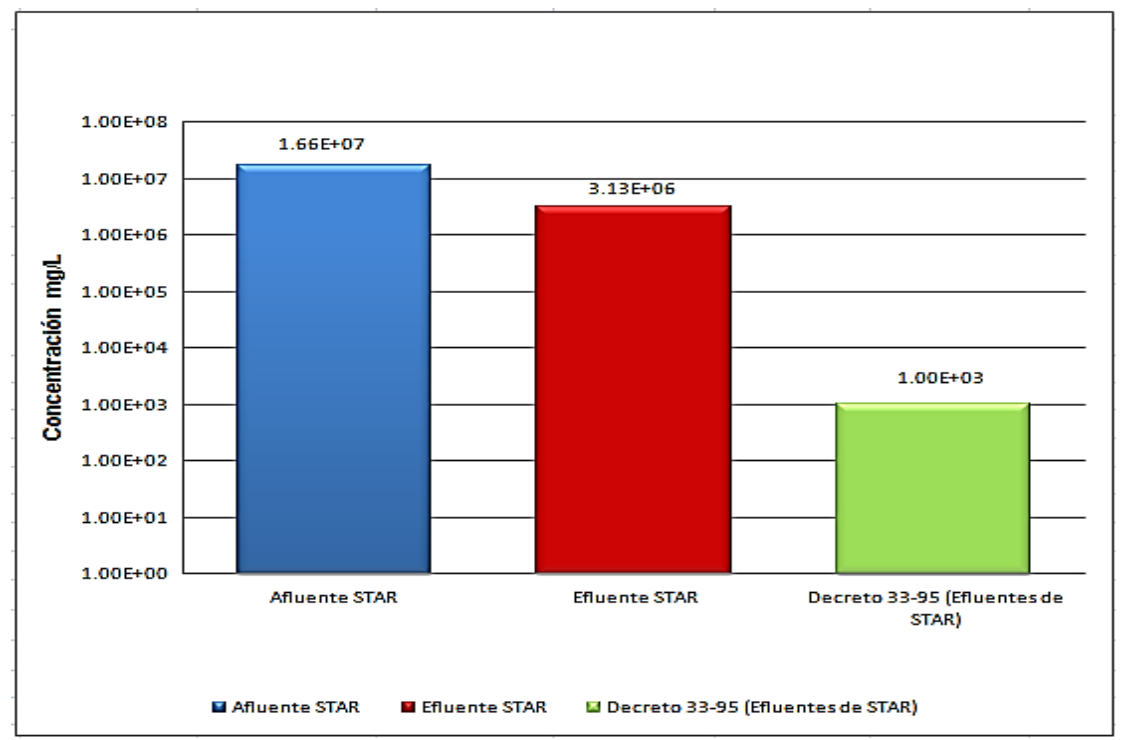

Gráfico 3: Concentración promedio de coliformes fecales en el afluente y efluente del STAR

De acuerdo al promedio de concentración en el afluente y efluente de $1.66 \mathrm{E}+07$ y de $3.13 E+06$, se en el grafico 1 , se observa que se obtiene una remoción de coliformes fecales de 1.0 ciclo logarítmico, lo cual es un valor limitante ya que la remoción es bastante baja, y esto se debe a la falta de mantenimiento de algunas unidades de tratamiento como los reactores UASB y las lagunas de estabilización, las cuales presentan maleza alrededor, acumulación de natas en los bordes y esquinas (lagunas), lo que afecta en el proceso de la fotosíntesis de algas y de la eliminación de bacterias coliformes.

\section{Carga orgánica}

Como análisis adicional se realizó el cálculo de la carga orgánica en términos de DBO5 y DQO que el STAR descarga al cuerpo receptor en este caso la quebrada "La Limonosa", resultando un valor de $402.19 \mathrm{Kg} /$ día con respecto a DBO5 y en cuanto a DQO fue de $1001.85 \mathrm{Kg} /$ día. En la tabla 3 , se muestran los resultados del cálculo de carga orgánica.

Tabla 3: Resultado de carga orgánica en términos de DBO y DQO que ingresan y egresan del sistema.

\begin{tabular}{cccc}
\cline { 2 - 4 } & Carga $\mathrm{DBO}_{5}$ (Kg/día) & Carga DQO (Kg/día) & \% Remoción \\
\hline Entrada general & 6084.42 & 8735.53 & 93.39 \\
Salida general & 402.19 & 1001.85 & 88.53 \\
\hline
\end{tabular}

Los valores anteriores son de gran importancia conocerlos ya que nos indican la cantidad máxima aproximada de carga contaminante en términos de DBO5 y DQO que entran al sistema y lo que el STAR en general aporta a la quebrada "La Limonosa". 
La eficiencia remocional de carga orgánica del sistema en general en términos de DBO5 y DQO es de $93.39 \%$ y $88.53 \%$, estos porcentajes nos indican que el sistema de tratamiento trabaja eficientemente en la reducción de la carga orgánica.

\section{Determinación de la Carga orgánica total}

Tabla 4: Carga orgánica total a tratar y concentración teórica de $\mathrm{DBO}_{5}$

\begin{tabular}{cccc}
\hline Unidad & $\begin{array}{c}\text { Población conectada } \\
\text { al alcantarillado }\end{array}$ & $\mathrm{DBO}_{5}$ Per cápita & Carga Orgánica \\
\hline STAR- Estelí & 121,688 & $50 \mathrm{gr}^{2} \mathrm{DBO}_{5} \mathrm{ppd}$ & $6,084.40 \mathrm{mg} \mathrm{DBO}_{5} / \mathrm{lt}$ \\
\hline
\end{tabular}

\section{Determinación de la Carga máxima Superficial}

Con este método estadístico se permite conocer el límite máximo de carga orgánica para lagunas facultativas el cual tiene que ser siempre mayor que las cargas que entran a las lagunas primarias (Facultativas), para que estas lagunas no corran el riesgo de volverse anaerobias; es decir que si sobrepasa el límite máximo las lagunas primarias dejarían de operar como lagunas facultativas, eliminando su estrato aerobio y convirtiéndose en anaerobio en toda su extensión.

Con los modelo de cálculos aplicados a continuación, se determinó la cantidad de materia orgánica promedio removida para lagunas facultativas tomando en cuenta la carga superficial aplicada a las lagunas.

Los resultados obtenidos se presentan en la siguiente tabla:

Tabla 5: Cálculos de carga superficial para lagunas primarias del STAR Estelí por medio de métodos estadísticos.

\begin{tabular}{|c|c|c|c|c|c|c|}
\hline $\begin{array}{l}\text { Csm } \\
\text { (yánez- } \\
1992)\end{array}$ & $\begin{array}{l}\text { Csa } \\
(90 \% \\
\text { Csm) }\end{array}$ & $\begin{array}{c}\text { Por } \\
\text { correlación } \\
\text { (Yánez - } \\
\text { CEPIS) }\end{array}$ & $\begin{array}{c}\text { Por } \\
\text { correlación } \\
\text { (Mc Garry- } \\
\text { Pescod) }\end{array}$ & $\begin{array}{c}\text { Por } \\
\text { correlación } \\
\text { (Mara y } \\
\text { Silva) }\end{array}$ & $\begin{array}{l}\text { Promedio } \\
\text { de } \\
\text { remociones }\end{array}$ & $\begin{array}{l}\text { Eficiencia } \\
\text { remocional }\end{array}$ \\
\hline $\begin{array}{c}357.4 \\
\mathrm{~kg} . \mathrm{DBO} / \\
\mathrm{Ha} \text { día }\end{array}$ & $\begin{array}{c}321.66 \\
\text { kg.DBO/ } \\
\text { Ha*día }\end{array}$ & $\begin{array}{c}267.02 \\
\mathrm{~kg} . \mathrm{DBO} / \\
\text { Ha*día }\end{array}$ & $\begin{array}{c}243.55 \\
\text { kg.DBO/ } \\
\text { Ha*día }\end{array}$ & $\begin{array}{c}256.11 \\
\text { kg.DBO/ } \\
\text { Ha*día }\end{array}$ & $\begin{array}{c}255.56 \\
\text { kg.DBO/ } \\
\text { Ha*día }\end{array}$ & $\begin{array}{c}79.45 \% \\
\text { kg.DBO/ } \\
\text { Ha*día }\end{array}$ \\
\hline
\end{tabular}

De acuerdo a los resultados obtenidos, la carga superficial máxima a aplicar para las lagunas facultativas del Sistema de Tratamiento de Aguas Residuales de la Ciudad de Estelí debe ser $321.66 \mathrm{~kg}$. DBO/ Ha*día, lo cual es un valor de gran importancia para evitar que las lagunas primarias reciban cargas orgánicas superiores al límite encontrado porque perderían su condición de lagunas facultativas. Por lo mencionado anteriormente podemos analizar que las cargas encontradas no están dentro del límite de carga superficial máxima para las lagunas del STAR Estelí. 
Con respecto a los valores obtenidos aplicando las diferentes correlaciones de carga superficial removida esperada, existe una leve variación, por lo cual de acuerdo a recomendaciones de Gámez (2009) se debe realizar un promedio general de las remociones esperadas.

Tabla 7: Cálculos de carga superficial para lagunas secundarias del STAR Estelí aplicando métodos estadísticos.

\begin{tabular}{|c|c|c|c|c|c|}
\hline Módulo & Unidad & $\begin{array}{c}\text { Carga } \\
\text { superficial } \\
\text { entrada } \\
\text { (Kg.DBO/Ha. } \\
\text { día) }\end{array}$ & $\begin{array}{c}\text { Carga } \\
\text { superficial } \\
\text { salida } \\
\text { (Kg.DBO/Ha. } \\
\text { día) }\end{array}$ & $\begin{array}{c}\% \text { de } \\
\text { Remoción }\end{array}$ & $\begin{array}{c}\text { \% Promedio } \\
\text { remoción } \\
\text { STAR }\end{array}$ \\
\hline \multirow{3}{*}{$\begin{array}{l}\varangle \\
\text { 을 } \\
\frac{0}{0} \\
\frac{0}{2}\end{array}$} & UASB & 7569.68 & 2892.70 & $61.79 \%$ & \multirow{3}{*}{$97.65 \%$} \\
\hline & L. Facultativa & 622.09 & 310.85 & $50.03 \%$ & \\
\hline & L. Maduración & 356.90 & 178.01 & $50.12 \%$ & \\
\hline \multirow{3}{*}{$\begin{array}{l}\infty \\
\text { 을 } \\
\frac{0}{0} \\
\stackrel{0}{\Sigma}\end{array}$} & UASB & 8346.53 & 3457.65 & $58.57 \%$ & \multirow{3}{*}{$97.76 \%$} \\
\hline & L. Facultativa & 794.86 & 603.94 & $24.02 \%$ & \\
\hline & L. Maduración & 673.62 & 186.58 & $72.30 \%$ & \\
\hline \multirow{3}{*}{$\begin{array}{l}0 \\
0 \\
\frac{0}{5} \\
0 \\
\sum\end{array}$} & UASB & 5770.12 & 3392.13 & $41.21 \%$ & \multirow{3}{*}{$96.88 \%$} \\
\hline & L. Facultativa & 745.52 & 385.83 & $48.25 \%$ & \\
\hline & L. Maduración & 444.43 & 180.25 & $59.44 \%$ & \\
\hline
\end{tabular}

En tabla anterior podemos observar las eficiencias de remoción obtenidas en las lagunas del STAR, las cuales no varían demasiado y son valores aceptables ya que se logra el cumplimiento de los rangos máximos establecidos en los Art. 22 y 23 del Decreto 33-95.

\section{CONCLUSIONES}

En base a los resultados obtenidos de los análisis de laboratorio realizados a las muestras extraídas del STAR, podemos concluir que el sistema de tratamiento trabaja eficientemente en la remoción de los parámetros fisicoquímicos establecidos en los Art. 22 y 23 del Decreto 33-95, a excepción del parámetro microbiológico de coliformes fecales que aun teniendo un aceptable porcentaje de remoción no es lo suficiente para cumplir con los límites máximos permisibles, lo cual afecta directamente al efluente ya que contiene un alto grado de contaminación para el cuerpo receptor y la población en general. 
El tiempo de retención hidráulica nominal, TRH, para la mayoría de los sistemas es menor como resultado del incremento de los caudales, y la mayoría de sistemas no cumplen la recomendación de la OMS de 10 días mínimas para remover huevos de helmintos en lagunas facultativas (Mara y Cairncross, 1989).

Como resultado de los caudales altos con menos TRH, en combinación a veces con una DBO5 alta en el afluente, la carga superficial orgánica para la laguna facultativa fue alta en la mayor parte de monitoreo.

Así también de acuerdo al valor promedio general de concentración de coliformes fecales obtenido de los análisis de laboratorio, podemos decir que el efluente no puede ser reutilizado para ninguna actividad agrícola porque incumple con el cap. 11 de la norma de reusó NTON 05 027-05 "Norma Técnica Ambiental para regular los sistemas de tratamiento de aguas residuales y su reuso".

Según la evaluación que se realizó sobre la operación y mantenimiento del sistema se puede decir que algunas unidades de tratamiento como los reactores y las lagunas de estabilización no reciben un mantenimiento adecuado lo cual afecta al funcionamiento del STAR y a la salud de la población debido a los malos olores que esta genera producto de la falta de limpieza de natas en la superficie de las unidades mencionadas.

De acuerdo a los resultados obtenidos a través del balance hídrico estos nos indican que existen pérdidas de hasta $30.04 \mathrm{lt} / \mathrm{s}$ en todo el sistema, debido a que influyo la evaporación durante el periodo que se realizó el aforo y hay que señalar que varias lagunas presentan un deterioro en sus taludes, lo cual favorece que las pérdidas de aguas residuales aumenten.

Se constató, que el sistema no posee una tabla con registros donde se permita traducir la lectura en caudal; unido a esto se expone el hecho la mala construcción de estas estructuras, por lo que se observó algunas fallas canales, USB entre otros.

En términos de operación, ningún operador ha monitoreado sus caudales-tampoco puede con las canaletas Parshall existentes-ni ha tomado muestras de rutina (in situ o para mandar al laboratorio) para analizar el funcionamiento del sistema. No se ha tomado un catastro de las conexiones al sistema de alcantarillado para tener un registro de las cargas pasadas, presentes y futuras. Y nadie ha monitoreado la profundidad de lodos en lagunas primarias.

El mantenimiento físico fue inadecuado en la mayoría del tiempo, pero muchas veces faltan herramientas adecuadas para, por ejemplo, la limpieza de natas. La mayoría de las instalaciones cuentan con personal adecuada, pero el personal frecuentemente requiere más capacitación sobre la operación y mantenimiento del sistema.

La sostenibilidad del sistema no parece adecuada por el momento. El sistema cuenta con un relativo apoyo técnico y económico por parte de ENACAL, y también presenta un estrés social por parte del público. 
Hay bastantes problemas como la necesidad de instalar canaletas Parshall que funcionen, monitoreo de caudales, catastro de conexiones, capacitación de operadores, y planes para la expansión del sistema para acomodar el crecimiento de la población.

\section{REFERENCIA}

Alcaldía municipal de Estelí. (18 de Septiembre de 2015). Alcaldía municipal de Esteli. Obtenido de Alcaldía de Esteli: http://www.alcaldiaesteli.gob.ni/index.php?option=com_content\&view=article\&id= $10 \&$ Itemid $=12$.

Asamblea Nacional de Nicaragua. (2000). Decreto $N^{\circ} 33-95$ :"Disposiciones para el control de la contaminación proveniente de las descargas de las aguas residuales domesticas, industriales y agropecuarias". Managua,Nicaragua.

Instituto Nicaragüense de Acueductos y Alcantarillado Sanitario (2004). Guias tecnicas para el diseño de alcantarillado sanitario y sistemas de tratamiento de aguas residuales. Managua,Nicaragua. Obtenido de www.inaa.gob.ni.

Mercado, A. (2013). www.aquaknow.net. Obtenido de www.aquaknow.net: http://www.aquaknow.net/en/system/files/3.Lagunas\%20de\%20estabilizaci\%C3\% B3n_0.pdf.

Centro Panamericano de Ingeniería Sanitaria y Ciencias del. Ambiente. (1996). Propuesta Metodológica Evaluación de Lagunas de Estabilización. Lima.

Centro Panamericano de Ingeniería Sanitaria y Ciencias del. Ambiente.. (2005). Guía para el diseño de tanques sépticos,tanques Imhoff y lagunas de estabilización. Lima.

Tchobanoglous, G. (2000). Tratamiento de aguas residuales en pequeñas poblaciones. Bogotá, Colombia: McGraw Hill.

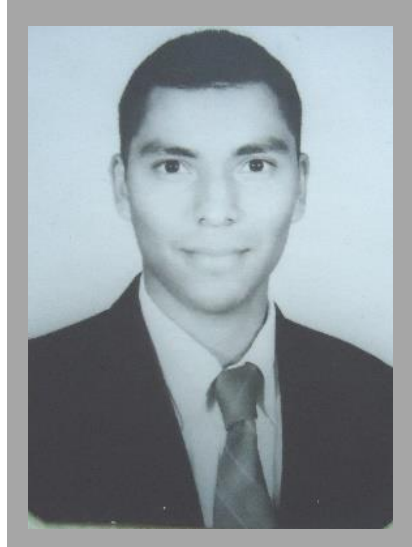

Henry Javier Vílchez Pérez: Es graduado de Ingeniero Civil, con Master en Ingeniería Ambiental del Programa de Investigación Estudios Nacionales y Servicios Ambientales de la Universidad Nacional de Ingeniería. Es profesor de las asignaturas de ingeniería sanitaria y gestión integra de residuos sólidos. Su área de investigación es la disposición final de residuos sólidos y subproductos y sistemas de tratamiento de agua residual. 